\section{Early Field Performance of Micropropagated Japanese Persimmon Trees}

\author{
Takuya Tetsumura and Hisajiro Yukinaga ${ }^{1}$ \\ Experimental Farm, Faculty of Agriculture, Kyoto University, Takatsuki, \\ Osaka 569-0096, Japan
}

\author{
Ryutaro Tao \\ Laboratory of Pomology, Graduate School of Agriculture, Kyoto University, \\ Sakyo-ku, Kyoto 606-8502, Japan \\ Additional index words. fine root, seedling stock, taproot, transplantation shock, Diospyros \\ kaki
}

\begin{abstract}
Growth of micropropagated Japanese persimmon trees (Diospyros kaki L. cv. Nishimurawase) during the initial 3 years after field establishment was compared with that of grafted trees on seedling stocks. Judging from the mean length of annual shoots per tree and the yearly increases in height, trunk diameter, and top and root dry mass, the grafted trees on seedling stocks grew poorly during the first and second growing seasons, while micropropagated trees, raised in an outdoor nursery, developed poorly only during the first growing season. In contrast, micropropagated trees raised in pots fared well soon after field establishment. These trees had more fine than middle and large roots; in contrast, grafted trees on seedling stocks had one large taproot, which died back to some extent after field establishment, with few fine roots.
\end{abstract}

Japanese persimmon is particularly prone to transplantation shock (Izaki et al., 1958; Kitagawa and Glucina, 1984). Nursery plants grafted on seedling stocks often grow poorly during the first growing season after they are transplanted from outdoor nurseries to orchards. If irrigation is inadequate, poor growth continues for two or more years, and some of them eventually die. This shock results from root pruning and drying during transplanting, and from a lack of lateral and fine roots (Izaki et al., 1958). Tao et al. (1994) reported that micropropagated trees developed many lateral and fine roots, whereas seedlings had one vigorous taproot from which only a few lateral roots elongated, and suggested that micropropagation could alleviate transplantation shock. To our knowledge, no previous reports compared the growth of grafted trees on seedling stocks with that of micropropagated trees after transplanting. The purpose of this study was to evaluate the growth of own-rooted and micropropagated Japanese persimmon trees after field establishment in comparison with that of grafted trees on seedling stocks.

Received for publication 24 July 1997. Accepted for publication 7 Nov. 1997. We acknowledge the technical assistance of K. Konishi and K. Tanaka. The cost of publishing this paper was defrayed in part by the payment of page charges. Under postal regulations, this paper therefore must be hereby marked advertisement solely to indicate this fact.

${ }^{\prime}$ Current address: Dept. of Biotechnological Science, School of Biology Oriented Science and Technology, Kinki Univ., Wakayama 649-6433, Japan.

\section{Materials and Methods}

Three types of 'Nishimurawase' Japanese persimmon trees were studied. Twelve trees grafted on 1-year-old seedlings in Spring 1992 (G) were dug from an outdoor nursery in midDec. 1992, and were heeled-in in moist sand after washing the soil off the roots. Twentyfour micropropagated trees (M), which were derived from shoot tips and maintained in vitro for 2 years, were obtained as described previously (Tetsumura et al., 1993). One-half of them were planted in the nursery in May 1992 and were treated similarly to the grafted trees $(\mathrm{MN})$. The other half were grown in pots until field establishment (MP).

In Jan. 1993, the shoots and roots of three trees of each type were oven-dried at $80^{\circ} \mathrm{C}$ for $3 \mathrm{~d}$ and then weighed. The roots were classified into three groups according to their diameters measured after drying.

On 5 Mar. 1993, nine trees of each type were planted in clay loam at an orchard of the Experimental Farm of Kyoto Univ., and were mulched with black 1.5 -m-wide nonwoven fabric. A 2.5-cm-diameter steel pipe stake was driven beside each tree for training and support, and extended $3.0 \mathrm{~m}$ from the soil surface. The within-row spacing was $1.3 \mathrm{~m}$, and the between-row spacing was $6.5 \mathrm{~m}$. The experimental design was a randomized complete block with three replications (trees). In Jan. 1994, 1995, and 1996, one tree of each type was removed from every block, and its shoot and root dry masses were checked as described above. In this manner, the within-row spacing was increased every year. For the trees removed in 1996, the following growth indices were recorded: 1) trunk diameter at $10 \mathrm{~cm}$ above the soil surface both at planting and each December; 2) the length and number of annual shoots per tree each November; and 3) tree height both at planting and each November. In 1993-95, each tree received a total of 200,300 , or $750 \mathrm{~g}$ of $8 \mathrm{~N}-8 \mathrm{P}-8 \mathrm{~K}$ fertilizer per year as a split application. None of the trees were pruned. All flower buds were thinned before flowering. Insecticides and fungicides were applied when necessary.

Except for annual shoot length, all data were subjected to analysis of variance (ANOVA) and means were separated by Duncan's multiple range test. The data for annual shoot length were subjected to twoway ANOVA. Since the tree type $\times$ year interaction was significant, means were separated by Tukey's honestly significant difference (HSD).

\section{Results and Discussion}

There were considerable differences in size among the types of nursery stock before planting (Fig. 1). Hammerschlag and Scorza (1991) pointed out the difficulty of comparing trees grafted on seedling stocks vs. micropropagated trees. We decided to use the nursery stocks in this study because all of them were "1-yearold nursery stocks," whose scions had grown outdoors for one growing season.

Shoots of $\mathrm{G}$ trees developed poorly during the first and second growing seasons, as did those of $\mathrm{MN}$ trees during the first growing season (Fig. 2). However, MP trees fared well soon after field establishment. Ogawa et al. (1994) used mean shoot length per tree as an index of transplantation shock in the nursery stock studies of Japanese persimmon. In the present study, although MP trees were shorter than the other tree types at planting (Fig. 3), the annual shoot length was greater. We conclude that these trees were less affected by transplantation shock. Initially, MP trees had fewer shoots than did the other tree types, because they were smaller and had fewer buds, but no difference was apparent at the end of the experiment (data not presented).

The height of $\mathrm{G}$ trees increased by only $2 \%$ to $4 \%$ of their previous years' levels during the first and second growing seasons; the same was true of $\mathrm{MN}$ trees during the first growing season. In contrast, the height of MP trees increased by $>50 \%$ every year (Fig 3 ). Therefore, although the MP trees were initially onethird as tall as the other tree types, all were the same height by the end of the experiment. In addition, the yearly increase in trunk diameter paralleled the increase in tree height (data not presented).

During the first two growing seasons, the dry mass of the tops of MP trees reached values seven or eight times as great as that of the previous years (Table 1). However, the dry masses of the tops of $\mathrm{G}$ trees during the first two seasons and MN trees during the first season did not exceed twice that of the previous year.

After the first growing season, the dry mass of the roots of $\mathrm{G}$ trees decreased (Table 1). Japanese persimmon roots, especially the larger 


\section{Propagation \& Tissue Culture}

ones, easily become rotten due to root pruning (Maeda and Yoshioka, 1955). In this study, the roots spread out in the nursery. We could not dig up the trees without cutting the roots, and some parts of the large taproots of the seedlings were also cut off. Upon digging up the seedlings in Jan. 1994, we discovered that their taproots had died back to some extent and very few new fine roots had emerged from them. This root damage and underdevelopment may have caused the poor growth of $\mathrm{G}$ trees after field establishment. 1-Naphthaleneacetic acid possibly could be applied to overcome transplantation shock by promoting new root development (Izaki et al., 1960).

Before planting, the dry matter of roots of MP trees was distributed more to fine than to middle and large roots (Table 2). On the other hand, only $14 \%$ of the root dry matter of the $G$ trees was in the fine roots. The distribution of the dry matter of roots of MN trees to fine roots was intermediate between those of the other two tree types. This tendency was consistent with the degree of tree vigor after field establishment. We could not estimate tree vigor after field establishment from the top : root ratio of nursery stocks, because each of the tree types had similar ratios before planting.

The results obtained in this study agree with other reports on the transplanting of Japanese persimmon seedling stocks (Izaki et al., 1958; Ogawa et al., 1994), although this is the first report describing the transplantation of micropropagated trees. During the first few years after field establishment, other micropropagated fruit trees have also exhibited growth patterns different from those of conventionally propagated trees (Hammerschlag and Scorza, 1991; Larsen and Higgins, 1990; Zimmerman and Miller, 1991). In order to determine the economic feasibility of micropropagation and to evaluate early field performance, long-term studies on the growth, precocity, and yield efficiency of Japanese persimmon are needed.

Our study demonstrated that transplantation shock can be alleviated in micropropagated Japanese persimmon trees. Currently, Japanese persimmon trees are severely pruned to alleviate transplantation shock. This procedure is unnecessary if MP trees are used. Our study demonstrated that MN trees recovered from transplantation shock sooner than $\mathrm{G}$ trees. No significant differences were observed between micropropagated trees and grafted trees on seedling stocks 3 years after planting.

\section{Literature Cited}

Hammerschlag, F.A. and R. Scorza. 1991. Field performance of micropropagated own-rooted peach trees J. Amer. Soc. Hort. Sci. 116:1089-1091.

Izaki, M., A. Itakura, and K. Kashimura. 1958. Studies on the reduction of the transplanting injury in Japanese persimmon trees: I. Influence of root pruning and the drying of soil on sprouting and the growth of Japanese persimmon seedling (in Japanese with English summary). Scientific Rpt. Faculty Agr. Ibaraki Univ. 6:7-14.

Izaki, M., A. Itakura, and K. Kashimura. 1960. Studies on the reduction of the transplanting injury in Japanese persimmon trees: II. Effect of potassium $\alpha$-naphthaleneacetate on rooting and

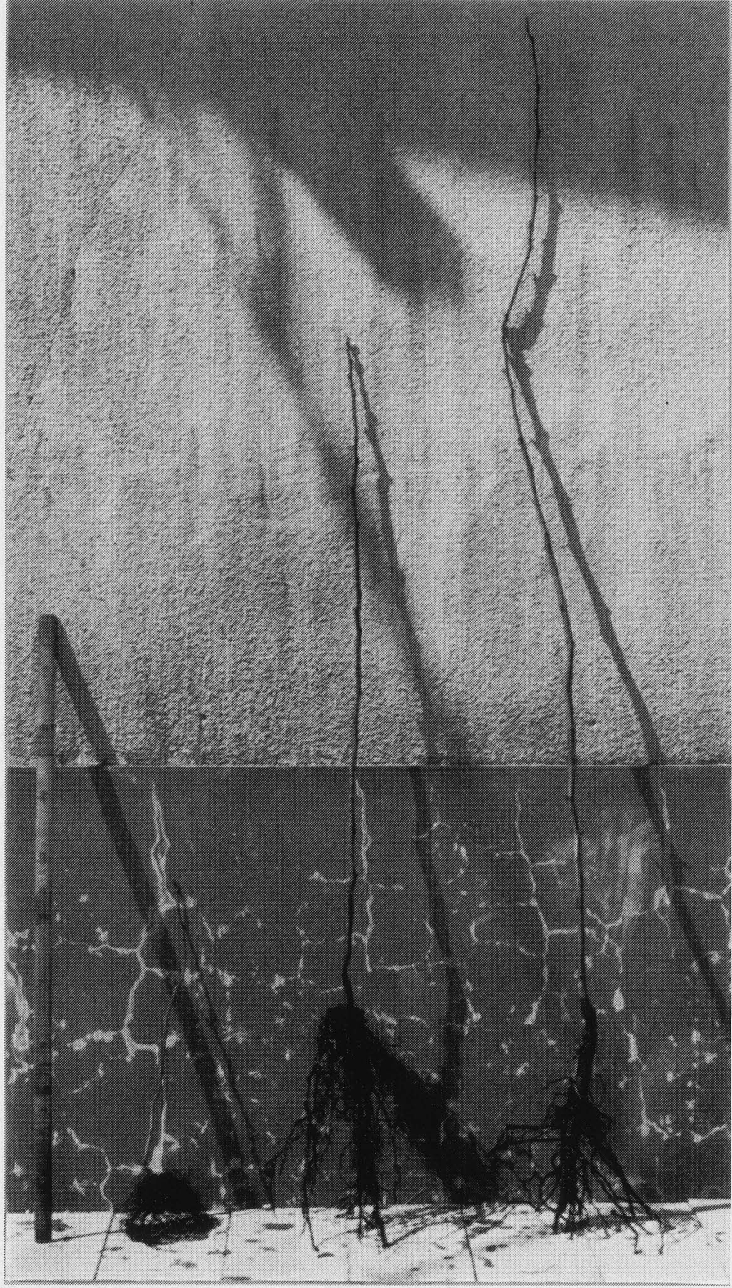

Fig. 1. The appearance of 'Nishimurawase' Japanese persimmon nursery stocks before planting (from left to right): micropropagated and raised in pot (MP); micropropagated and raised in outdoor nursery (MN); and grafted on seedling and raised in outdoor nursery $(\mathrm{G})$. Scale bar $=1 \mathrm{~m}$.

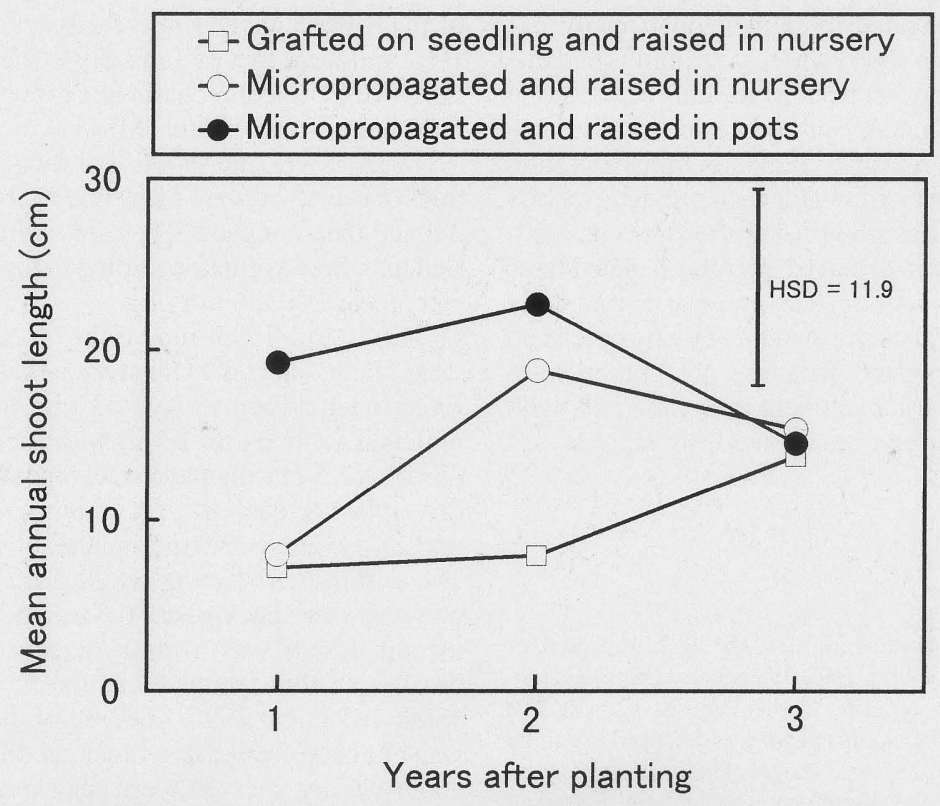

Fig. 2. Effect of method of propagation and handling on mean annual shoot length of 'Nishimurawase' Japanese persimmon trees after planting. Vertical bar $=$ HSD $(P \leq 0.05)$. Each point represents a mean, $\mathrm{n}=3$ 


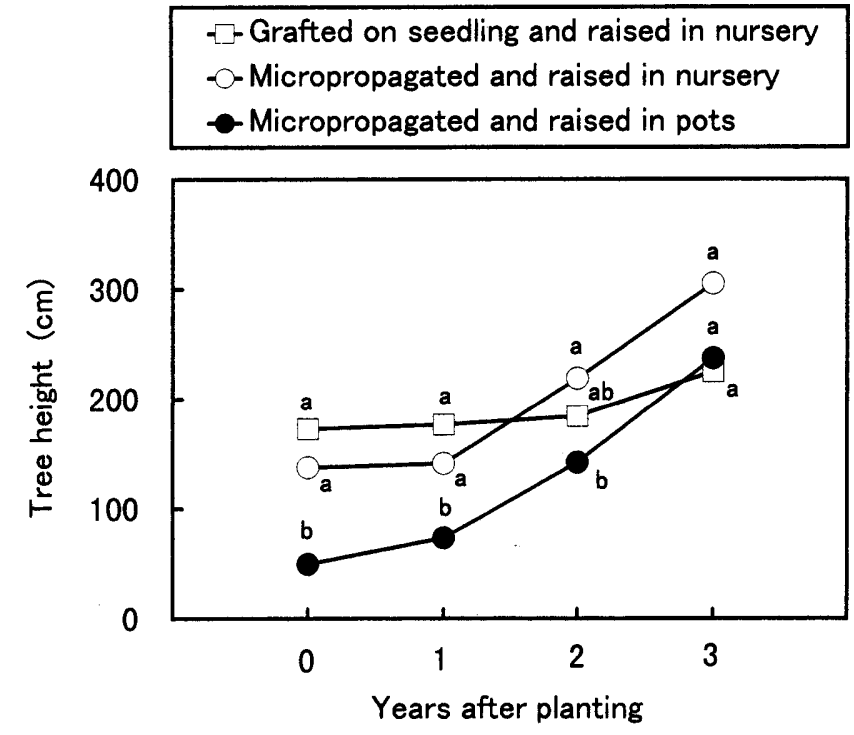

Fig. 3. Effect of method of propagation and handling on tree height of 'Nishimurawase' Japanese persimmon after planting. The values of year 0 were measured at planting. Within years, means with the same letter are not significantly different by Duncan's multiple range test at $P \leq 0.05$. Each point represents a mean, $\mathrm{n}=3$. new shoot growth of transplanted persimmon trees (in Japanese with English summary). J. Jpn. Soc. Hort. Sci. 29:219-222.

Kitagawa, H. and P.G. Glucina. 1984. Persimmon culture in New Zealand. Sci. Info. Publishing. Ctr., Wellington.

Larsen, F.E. and S.S. Higgins. 1990. Early field performance of several self-rooted, micropropagated apple cultivars vs. trees on seedling or $\mathbf{M}$ 7a rootstocks. Fruit Var. J. 44:185-192.

Maeda, S. and S. Yoshioka. 1955. An observation on root pruning of Japanese persimmon (in Japanese). Agr. Hort. 30:593-594.

Ogawa, S., Y. Sato, T. Takano, and A. Sugimoto. 1994. Studies on the increase in yield of Japanese persimmons with the ageing nursery stock and regulation of vegetative growth (in Japanese). Bul. Fukui Agr. Expt. Sta. 31:33-43.

Tao, R., J. Ito, and A. Sugiura. 1994. Comparison of growth and rooting characteristics of micropropagated adult plants and juvenile seedlings of persimmon (Diospyros kaki L. ). J. Jpn. Soc. Hort. Sci. 63:537-541.

Tetsumura, T., R. Tao, and H. Yukinaga. 1993. Factors influencing acclimatization of 'Nishimurawase' Japanese persimmon micropropagules and their field performance (in Japanese with English summary). J. Jpn. Soc. Hort. Sci. 62:533-538.

Zimmerman, R.H. and S.S. Miller. 1991. Orchard growth and fruiting of micropropagated apple trees. J. Amer. Soc. Hort. Sci. 116:780-785.

Table 1. Effects of method of propagating and handling 'Nishimurawase'Japanese persimmon trees on top and root dry mass.

\begin{tabular}{|c|c|c|c|c|c|c|c|c|c|c|}
\hline \multirow[b]{3}{*}{ Code } & \multirow{3}{*}{$\begin{array}{l}\text { Method of } \\
\text { propagation }\end{array}$} & \multirow{3}{*}{$\begin{array}{l}\text { Type of } \\
\text { nursery }\end{array}$} & \multicolumn{4}{|c|}{ Dry mass of top (g) } & \multicolumn{4}{|c|}{ Dry mass of roots $(\mathrm{g})$} \\
\hline & & & \multicolumn{4}{|c|}{ Year after planting } & \multicolumn{4}{|c|}{ Year after planting } \\
\hline & & & $0^{y}$ & 1 & 2 & 3 & 0 & 1 & 2 & 3 \\
\hline $\bar{G}$ & Grafted on seedling & Outdoors & $72.2 \mathrm{a}^{\mathrm{x}}$ & $93.2 \mathrm{a}$ & $173 \mathrm{a}$ & $801 \mathrm{a}$ & $116.2 \mathrm{a}$ & $71 \mathrm{~b}$ & $252 \mathrm{a}$ & $\overline{774 a}$ \\
\hline $\mathrm{MN}$ & Micropropagated & Outdoors & $41.9 \mathrm{~b}$ & $68.6 \mathrm{~b}$ & $525 \mathrm{a}$ & $1201 \mathrm{a}$ & $45.7 \mathrm{~b}$ & $112 \mathrm{a}$ & $746 \mathrm{a}$ & $1072 \mathrm{a}$ \\
\hline MP & Micropropagated & Pot & $5.2 \mathrm{c}$ & $44.2 \mathrm{c}$ & $315 \mathrm{a}$ & $888 \mathrm{a}$ & $7.6 \mathrm{c}$ & $101 \mathrm{a}$ & $416 a$ & $1050 \mathrm{a}$ \\
\hline
\end{tabular}

${ }^{2}$ Data represents mean, $\mathrm{n}=3$

${ }^{\mathrm{y}}$ Before planting.

${ }^{\times}$Mean separation within columns by Duncan's multiple range test at $P \leq 0.05$.

Table 2. Effects of method of propagating and handling 'Nishimurawase' Japanese persimmon trees on distribution of root dry matter before planting in the field. ${ }^{\mathrm{Z}}$

\begin{tabular}{|c|c|c|c|c|c|c|c|c|}
\hline \multirow[b]{2}{*}{ Code } & \multirow{2}{*}{$\begin{array}{l}\text { Method of } \\
\text { propagation }\end{array}$} & \multirow{2}{*}{$\begin{array}{l}\text { Type of } \\
\text { nursery }\end{array}$} & \multicolumn{3}{|c|}{ Dry mass $(\mathrm{g})$} & \multicolumn{3}{|c|}{ Dry-matter distribution (\%) } \\
\hline & & & Large $^{y}$ & Middle & Fine & Large & Middle & Fine \\
\hline$\overline{\mathrm{G}}$ & Grafted on seedling & Outdoors & $69.2 \pm 6.7^{x}$ & $30.2 \pm 8.7$ & $16.8 \pm 2.6$ & $61 \mathrm{a}^{\mathrm{w}}$ & $25 \mathrm{ab}$ & $\overline{14 \mathrm{~b}}$ \\
\hline MN & Micropropagated & Outdoors & $12.3 \pm 3.0$ & $21.7 \pm 2.3$ & $11.7 \pm 2.3$ & $26 \mathrm{~b}$ & 49 a & $25 a b$ \\
\hline MP & Micropropagated & Pot & $2.3 \pm 0.6$ & $1.2 \pm 0.2$ & $4.1 \pm 0.2$ & $29 \mathrm{~b}$ & $16 \mathrm{~b}$ & $55 \mathrm{a}$ \\
\hline
\end{tabular}

${ }^{2}$ Data represents mean, $\mathrm{n}=3$

'Large roots are $>5 \mathrm{~mm}$ in diameter, middle are $2-5 \mathrm{~mm}$, and fine are $<2 \mathrm{~mm}$.

${ }^{x}$ Mean \pm SE.

"Mean separation within columns by Duncan's multiple range test at $P \leq 0.05$. 